DIRECTIO SPECULANTIS O PROBLEMA TRINITÁRIO EM

NICOLAU DE CUSA

Directio speculantis: The Trinitarian problem by Nicholas of Cusa

Federico Croci $^{1}$

\begin{abstract}
RESUMO
O artigo explora a teologia trinitária de Nicolau de Cusa, destacando a tensão subjacente entre a retomada da exegese neoplatônica de Proclo e a necessidade de fundar a natureza trinitária do princípio absoluto. Relendo o tema da docta ignorantia à luz dos nomina Dei do non aliud e do possest, o artigo aprofunda progressivamente o problema no desenvolvimento das obras do cardeal, chegando a mostrar a impossibilidade de conciliar a teologia trinitaria cristã com a abordagem henológica do neoplatonismo grego, da qual decorre a impossibilidade de resolver as aporias relativas à personalidade do princípio e às relações entre Deus e as criaturas.

Palavras-chave: Nicolau de Cusa. Neoplatonismo. Teologia. Trindade. Henologia.
\end{abstract}

\begin{abstract}
The paper explores Nicholas of Cusa's Trinitarian theology, highlighting the underlying tension between the resumption of Proclus' exegesis and the necessity to found the Trinitarian nature of the absolute principle. Rereading the theme of the docta ignorantia in the light of the nomina Dei of the non aliud and the possest, the analysis follows the progressive deepening of the problem in the development of the cardinal's works, in order to show the impossibility of reconciling the Christian theology with the henological approach of Greek Neoplatonism, from which it follows the impossibility of resolving the aporias relating to the personality of the principle and to the relations between God and creatures.
\end{abstract}

Keywords: Nicholas of Cusa. Neoplatonism. Theology. Trinity. Henology.

\footnotetext{
${ }^{1}$ Doutor em Filosofia pela Università Vita-Salute San Raffaele (2017) e Pós-doutorado pela Universite de Fribourg (2019). Pós-doutorando pela Universidade Federal de São Paulo, processo n ${ }^{\circ}$ 2018/14732-7, Fundação de Amparo à Pesquisa do Estado de São Paulo (FAPESP). Email: f.croci@outlook.it. ORCID: https://orcid.org/0000-0002-3395-4543.
} 


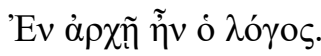

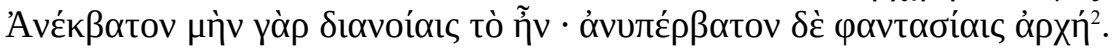

Matto è chi spera che nostra ragione possa trascorrer la infinita via che tiene una sustanza in tre persone ${ }^{3}$.

\section{Nulla proportio}

O que move o autêntico filosofar, lembra Nicolau de Cusa ao leitor, é muitas vezes o passo descuidado de publicar os próprios escritos, mesmo que sejam considerados de pouco valor (meas barbaras ineptias incautius pandere attempto $)^{4}$. Essa audácia, que parece desmentir as advertências neoplatônicas para evitar a arrogância pomposa da alma, deriva da desproporção inerente a qualquer tentativa de pensar a origem.

Nicolau de Cusa concebe o princípio como infinito segundo a infle-

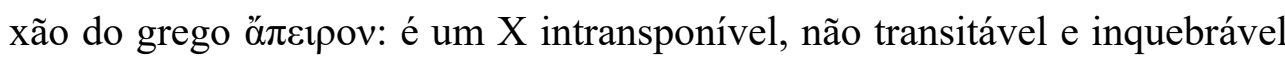
para quem nele está contido, como as redes de pesca; não uma quantidade ilimitada, mas a expressão da impossibilidade de estabelecer pontos de referência - como em um círculo, que não tem começo, nem meio, nem fim. $\mathrm{O}$

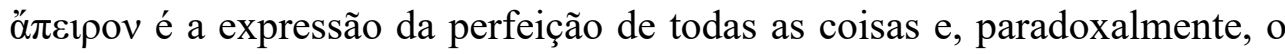
limite que lhes inere: qualquer esforço para conceituar a origem será ao mesmo tempo necessário e vão. Limite sem limitação, Deus complica em si mesmo todo limite limitados.

A audácia dessas noções justifica o incultus stilus que caracteriza, por sua própria admissão, a prosa do cardeal $^{6}$. A declaração é sutilmente paradoxal, especialmente quando seja apontado que ele retoma a expressão docta ignorantia de um excelente orador do calibre de Agostinho de Hipo-

2 BASÍLIO DE CESAREIA. De Spiritu Sancto, VI, 14, 89a 25-26: «No princípio era o Verbo. Sem êxito para as reflexões, o "era"; intransponível para as representações, o princípio».

3 DANTE ALIGHIERI. Purgatorio, III, vv. 34-36.

4 NICOLAU DE CUSA. De docta ignorantia, I, prólogo. A edição crítica do texto latino de todas as obras é a publicada por Meiner, Leipzig/Hamburg 1932 ss. As duas exceções são o De docta ignorantia e o De non aliud. Para o primeiro, a edição de referência é a editio minor da Academia de Heidelberg, que melhora a editio maior do 1932. Para o segundo, a edição de referência é: NICOLÁS DE CUSA. Acerca de lo no-otro o de la definición que todo define. Edição: Jorge M. Machetta y Klaus Reinhardt. Buenos Aires: Biblos, 2008.

5 NICOLAU DE CUSA. De principio, 33.

6 NICOLAU DE CUSA. De concordantia catholica, 2, 3. 
na, que a usa em referência à natureza da oração ${ }^{7}$, mas a declina de acordo com o significado de Boaventura, que a utiliza para designar as trevas e o êxtase que impedem a visio divina ${ }^{8}$. O esclarecimento não é de pouca importância: procliano por formação, Nicolau de Cusa acredita que a essência do intellectus, se considerada do ponto de vista do ato, é uma coincidência do intelecto e do viver ${ }^{9}$. No ataque do De non aliud, o cardeal rejeita a abordagem da secta aristotelica, que faz da definitio, entendida como a união de ratio e oratio, o princípio do conhecimento, sendo assim reduzida à apreensão e expressão conceitual da quidditas do que é o objeto de investigação: como pode viver o intelecto, pergunta o cardeal, se não entende de onde vem tudo, incluído si mesmo?

Essas primeiras notações dão a ideia da modernidade avassaladora da filosofia de Nicolau de Cusa. A análise que os três primeiros capítulos do primeiro livro do De docta ignorantia dedicam a Deus não se realiza segundo o adágio clássico da quaestio an Deus sit, mas parte do exame dos limites do conhecimento: antes de investigar se Deus existe ou não, é necessário investigar o que o homem sabe e não sabe e, em particular, o que sabe sobre o seu próprio não saber. Essa operação de elevação e purificação progressiva das noções, que o cardeal designa com o termo manuductio, é descrita como pegar o aprendiz pela mão, acompanhando-o passo a passo até que ele amadureça a capacidade de andar sozinho.

A de Nicolau de Cusa é, portanto, uma crítica da razão pura: uma crítica que flexiona o ato intelectual, entendido pelos escolásticos como simples e imediato, sobre si mesmo. Nessa reflexão, a estrutura e a certeza do conhecimento entram em xeque. Se o conhecimento é entendido como uma comparação do conhecido com o desconhecido, que permite que o desconhecido se dê a conhecer por meio de um processo cognitivo inesgotável, ao aumentar quantitativamente o conhecimento, segue-se que a comparatio ultima, aquela entre o finito e o infinito, clarifica que qualquer finito, seja conhecido ou desconhecido, é qualitativamente diferente do infinito: a

7 AGOSTINHO DE HIPONA. Epistula 130, XV, 28.

${ }^{8}$ BOAVENTURA DE BAGNOREGIO. Breviloquium, V, 6, 8.

9 NICOLAU DE CUSA. De docta ignorantia, III, 10, 241, 11-12. 
comparatio entre o princípio e a criatura evidencia a desproporção de toda proporção comparativa estabelecida pelo intelecto.

Rejeitado é, em primeiro lugar, o princípio da analogia entis. $\mathrm{O}$ alvo crítico, com toda a probabilidade, é Tomás, que defendeu o princípio, embora admitindo a desproporção entre Deus e suas criaturas, afirmando que a nulla proportio indica apenas a impossibilidade de atingir uma cognitio perfeita da essência divina, enquanto a demonstração da existência divina é garantida pela relação causal, que permite a inferência a posteriori $^{10}$. A impossibilidade de qualquer investigação sobre Deus, por outro lado, caracteriza a releitura do neoplatonismo própria de Nicolau de Cusa: a afirmação nulla quaestio de Deo marca a passagem definitiva da sacra doctrina à sancta ignorantia.

A discrepância da mensuração em relação ao mesurado (seja finito ou infinito) desequilibra a espinha dorsal do aristotelismo escolástico, a $a d a-$ equatio rei et intellectus. O princípio que se procura é a perfeita coincidentia contradictoriorum, porque não tem um oposto: a lógica da distinção do Sofista, segundo a qual uma determinada coisa é si mesma na medida em que não é todas as outras (finita et terminata est), é realizada no ensino do Parmênides, onde é mostrado que o máximo é o mínimo, o uno é os muitos, o transcendente é o imanente. A lógica escolástica, regida pelo princípio da não contradição, não pode escapar da forma opositiva que reduze Deus a ser o aliquid ou nihil: na lógica aristotélica é contraditório que haja uma média entre ser algo e ser nada. A nova figura do idiota se distancia tanto daquela do orator humanista como daquela do philosophus aristotélico: a comprehensio é sublimada na admiratio, o que nos faz adorar o que, ignorado, é envolto pela caligem luminosa da coincidentia contradictoriorum.

Innominabiliter nominabile esse ${ }^{11}$. Ao fazer da contradição a cifra da origem, o cardeal torna a coincidentia oppositorum numa coincidentia contradictoriorum $^{12}$. No auge, o intelecto encontra-se despojado de sua própria

10 TOMÁS DE AQUINO. Summa theologiae, I, q. 2, a. 2. Cfr. anche De veritate, q. I, a. 12 , resp.: «Quiditas rei est proprium obiectum intellectus».

${ }^{11}$ NICOLAU DE CUSA. De docta ignorantia, I, 5, 13, 2.

$12 \mathrm{Na}$ lógica aristotélica, os termos que se opõem em uma relação são ditos opostos (por exemplo, mãe e filha), enquanto os termos maximamente diferentes dentro do mesmo gênero são ditos contrários (para o gênero cor, branco e preto). Por outro lado, aqueles termos que não são predicáveis do mesmo sujeito são ditos contraditórios. A expressão coincidentia contradictoriorum é preferida por Nicolau de Cusa à de coincidentia oppositorum, pois 
lógica, reduzido a uma contradição, embora neste conceito supremo, que se ergue como numa parede, nada do divino ainda brilhe ${ }^{13}$. No conceito da coincidentia contradictoriorum, Deus está sempre presente intellectualiter, nunca divinaliter. Prenunciando o princípio, o intelecto só pode identificar reflexivamente a positio de qualquer conceito com a imediata ablatio dele: a visio intellectualis, que no aristotelismo indica a capacidade do intelecto de apreender intuitivamente os primeiros princípios do conhecimento, se identifica com a faculdade arquitetônica da mente (apex mentis) em que se contempla a impossibilidade de qualquer conhecimento conceitual de Deus, tornando o intelecto em algo de constitutivamente non satiabilis.

Na construção da theologia circularis, que rejeita a lógica aristotélica da oposição, todos os predicados se predicam mutuamente e todos se dissolvem no infinito divino, alheios a qualquer oposição finita. $\mathrm{O}$ afastamento de Aristóteles, se permite a Nicolau de Cusa enxertar uma nova inspiração na reflexão teológica, o leva, porém, a aporias tipicamente neoplatônicas: como pensar a passagem do uno aos muitos? Como conceber o surgimento da diferença e da divisão desde o que é indiferente e simples? A estes se acrescenta outro, derivado da imensa tentativa de conciliar o princípio único dos exegetas pagãos de Platão com a novitas cristã: se Deus é concebido como criador, ou seja, achado em relação as suas criaturas, é certamente trino, mas em si mesmo não é pura infinitas irredutível a qualquer proporção, um abismo que precede a Trindade mesma ${ }^{14}$ ?

\section{Evangelium secundum Proclum?}

Neoplatônico e cristão, Nicolau de Cusa é herdeiro das aporias que caracterizam as duas tradições. A necessidade de pensar em um princípio que seja trinitário implica uma primeira escolha lexicológica: Deus é uno e trino ou trino e uno? Evidentemente, o cardeal prefere a primeira opção, aproximando-se de Proclo, de quem era um leitor voraz, do que dos seladores do dogma da igualdade substancial das três Pessoas divinas (ó $\mu$ oovoía),

a contradição expressa a forma máxima de oposição: enquanto a oposição não exclui a presença de um médium, a contradição não admite mediação, como os contraditórios não podem ser ambos verdadeiros ou ambos falsos.

13 NICOLAU DE CUSA. De visione Dei, X, 42, 7-19.

14 NICOLAU DE CUSA. De pace fidei, VII, 21, 9-11. 
ou seja, dos Padres Capadócios (Basílio de Cesareia, Gregório de Nazianzo, Gregório de Nissa).

Nos escritos dos Padres Gregos dominam as categorias de $\sigma 0 ́ v \tau \alpha \xi 1 \varsigma$ e $\sigma \chi \varepsilon ́ \sigma ı \varsigma$, pois a seus olhos só pensar na originalidade da relação pode salvar das derivas do subordinacionismo e do modalismo. O problema emerge claramente nas disputas contra o arianismo: como pensar a alteridade das Pessoas sem negar a identidade substancial delas? Se a alteridade fosse substancial, Ário e seus acólitos estariam certos. A modulação dos Capadócios é sutil: o que se pensa como substancial não é a alteridade das Pessoas, mas a sua distinção, tanto que podemos concluir que a substância de Deus é a própria distinção das três Pessoas, ou seja, a relação imanente que admite a distinção ao rejeitar a alteridade.

A escolástica se alimentará daquele paradoxo metafísico - pelo menos aos olhos da lógica que anima a secta aristotelica - que identifica o ser com uma entidade: a patrística grega vive disso, ainda mais surpreendente,

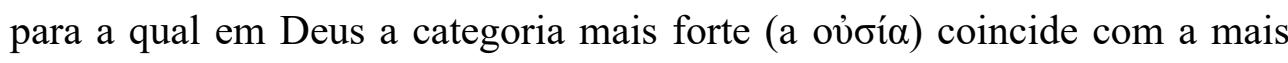
fraca (a $\sigma \chi \varepsilon ́ \sigma ı \varsigma)$. A opção trinitária dos Capadócios, segundo a qual a categoria da distinção não implica a da diferença, significa que pensar no Pai implica necessariamente pensar no Filho, visto que o Pai já tem em si a necessária relação com o Filho $^{15}$ : portanto, cada uma das três Pessoas é

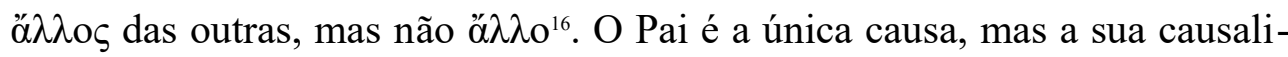
dade é relacional, tanto que o causado (o Filho) não é inferior à causa. Para os exegetas neoplatônicos (assim como para os arianos que, a partir de Constantino, serão acusados de serem seguidores de Porfírio) ${ }^{17}$, a distinção implica sempre a diferença, pois implica reciprocidade: ou se trata de uma alteridade modal, portanto fictícia (uma realidade única implica modos diferentes de ser pensada devido à finitude da mente humana), ou a uma alteridade real. A inconsistência dos cristãos é clara para eles: na esfera trinitária, eles deveriam optar pelo modalismo ou pelo subordinacionismo.

\footnotetext{
${ }^{15}$ Já Atanásio especificava, contra Ário, que o Filho é a condição da divindade do Pai: se não fosse o Filho, o Pai não seria Pai; portanto, a geração do Filho é necessária. Cfr. ATANÁSIO DE ALEXANDRIA. Contra Arianos, I, 20.

16 GREGÓRIO DE NAZIANZO. Epistula 101. A mesma coisa diz Agostinho, distinguindo alius e aliud. Cfr. AGOSTINHO DE HIPONA. De natura et origine animae, II, 5.

${ }^{17}$ COSTANTINO IMP. Epist. ad episc. et pleb. (apud Gelas, H.E., II, 36, e Sokrat., H.E., I, 9).
} 
Nas obras de Nicolau de Cusa, assim como naquelas de Proclo, a insistência na simplicidade do princípio é palpável. O cardeal específica continuamente que um e apenas um deve ser o primeiro princípio, já que uma e apenas uma deve ser a causa ${ }^{18}$ : se houvesse mais princípios, eles participariam de um único princípio anterior. O resultado é uma dramatização da aporia: diante de uma singularidade tão radical, como salvar a relação que caracteriza o Deus Trino? Em seus primeiros trabalhos, o cardeal reafirma que o princípio é um, mas três modos de ser se distinguem imediatamente nele: há um aspecto principiador que vem acompanhado de dois aspectos principiados $^{19}$. Mas o problema permanece: como evitar que a distinctio se traduza em alteritas?

Neste esforço de manter juntas duas tradições tão próximas quanto irreconciliáveis, Nicolau de Cusa luta não só na dificuldade de distinguir as três Pessoas divinas, mas também de diferenciar Deus do mundo. Se na esfera trinitária os dois perigos são os extremos do subordinacionismo e do modalismo, no campo ontológico o esforço é afastar-se tanto do transcendentismo típico da exegese procliana quanto do panteísmo gnóstico.

O cardeal aborda o problema de forma radical, optando por uma predição unívoca que une Deus e as criaturas. Prova disso é que o termo ens passa a significar a contração singular do princípio, e não mais algo uma alteridade substancial: o princípio, que é uma pura singularidade totalmente simples, ponto inefável que complica a totalidade das determinadas singularidades, é definido entitas absoluta. Assim, o problema fundamental passa a ser o de compreender que relação existe entre as entidades determinadas e a entidade suprema ou, por outras palavras, entre os seres contraídos e a entitas absoluta, entre as singularidades determinadas e a singularidade absoluta: explicitar esta ligação significa ser capaz de manter juntos a absoluta simplicidade do princípio e sua natureza trinitária. Como Deus, assim é a singularidade finita: ambas únicas, elusivas, inomináveis, contraditórias, porque irredutíveis à lógica determinante da oposição, que define diferenciando o sujeito do predicado. O que constitui os objetos de conhecimento é uma relação de mensurabilidade recíproca dentro de uma série homogênea,

\footnotetext{
18 NICOLAU DE CUSA. De pace fidei, VI, 17, 16-22.

19 NICOLAU DE CUSA. De principio, 9-10.
} 
que é precisamente porque consiste em termos mutuamente mensuráveis em virtude do número: Deus e as singularidades, entretanto, excedem a mensurabilidade garantida pela série contínua, sendo irredutíveis a predicados quantitativos.

A unidade do princípio e dos princípios é pensada dentro da esfera formal da univocidade. A infinitas que Deus complica é a mesma que o cosmos explica. Rejeitando a hierarquia hipostática procliana, que se constitui segundo um movimento vertical de séries de produção, Nicolau de Cusa pensa a participação do mundo não mais como comunicação de uma fonte transcendente infinitamente distante, mas, ao contrário, como presença constante do princípio nos principiados. $\mathrm{O}$ universo não é mais concebido como um somatório de entidades austeramente fechadas em si mesmas segundo uma ordem ascendente de limites, mas como uma correlação (conexio) infinitamente dinâmica em si mesma, onde o centro se converte em periferia e vice-versa. Em contraste com a causalidade vertical típica da exegese procliana, o cardeal reafirma uma causalidade imanente que é liberada em todas as direções e onde cada ponto, mesmo o mais periférico, tem o poder de se converter em um centro expansivo. A realidade passa a ser a modulação de um ritmo de variações, onde as alteridades se referem umas às outras, tornando-se símbolos divergentes e abertos a uma direcionalidade infinita. Nesse transumptio ad infinitum, o máximo e o mínimo tornam-se mutuamente inconcebíveis, e a mobilidade absoluta não se distingue mais da imobilidade total. Redefinindo constantemente seus próprios limites, cada figura contraída vai além do que parecia ser o limite de uma metamorfose inerente a cada momento.

Nicolau de Cusa estrutura uma apurada teologia simbólica, que visa manter Deus e as criaturas juntos, sem esgotar o princípio no mundo. A metáfora e o enigma, coagulados no instrumento da conjectura, permitem aludir sem ver. Os símbolos em que os nomina Dei consistem são os meios pelos quais complicação e explicação são mantidas juntas: a paradoxal convergência no princípio das divergências infinitas. Numa primeira tentativa de definir a questão, o cardeal introduz no De Genesi o conceito de idem absolutum, que não é nem pode ser idêntico ou diferente de nada: se fosse idêntico aos contraídos, seria diferente de si mesmo e idêntico ao seu pró- 
prio outro, ao passo que, se fosse diferente das realidades contraídas, seria de alguma forma afetado pela diferença e não seria mais o idem absolutum. As entidades contraídas, por outro lado, são idênticas a si mesmas no sentido de que são diferentes umas das outras e diferentes umas das outras por serem idênticas a si mesmas.

No entanto, esta solução apenas repropõe a antiga aporia neoplatônica: de onde vêm a alteritas e a diversitas que caracterizam as realidades finitas? A identificação das singularidades baseia-se, de fato, na impossibilidade de explicar o mecanismo interno da dialética de complicatio e explicatio. Se considerarmos cada singularitas como uma mônada na qual a totalidade do contraditório se reflete como negada, podemos equipará-la a um ponto inextenso: o desenvolvimento do cosmos é, portanto, uma série ininterrupta de pontos. Mas justapor ponto a ponto é como adicionar nada a nada: ainda assim, a linha nada mais é que o desenvolvimento que explica o ponto $^{20}$. A questão é o paradoxo da contínua interrupção e reconstituição da linha, em que o início e a continuidade da própria linha são concebidos em sua incompreensibilidade: a mesma mônada se repete, mas toda contração em que o movimento explicativo é pontualmente determinado repete o mesmo sempre como outro. Se o universo é a imagem de Deus como forma infinita, o que complica a infinidade de formas finitas que transfiguram, essa imagem de todas as imagens está envolta no paradoxo de ser ela mesma uma imagem. Assim entendida, a imago não pode ser diferente do imaginado: o signum sui nada mais é do que o signum alii, mas é precisamente a passagem do signo em todos os outros signos infinitos, a sua pericorese interna.

A impossibilidade de separar claramente o princípio do principado impede o cardeal siga Proclo até o fim: mesmo que os mestres neoplatônicos não tivessem nada a objetar da afirmação de que não pode haver uma multiplicidade separada do uno, eles não teriam aceitado a afirmação de que o uno é a hipóstase da multiplicidade, isto é, algo cuja simplicidade não se opõe simplesmente à infinidade dos muitos ${ }^{21}$. Ao contrário, Nicolau de Cusa define o princípio hypostasis omnium hypostaseum, pois é a razão do ser de

${ }^{20}$ NICOLAU DE CUSA. Dialogus de ludo globi, I, 9-10.

21 NICOLAU DE CUSA. De principio, 28. 
qualquer realidade que, paradoxalmente, não pode ser outro do determinado: se fosse outro do determinado, o princípio seria por sua vez determinado, e haveria ser uma necessidade de um princípio ainda anterior, causa da determinação. Ao mesmo tempo, comparada com a tradição procliana e dionisíaca, a negatio negationis não é mais entendida como a negação e a superação do pensamento que inevitavelmente acabam por opor o princípio, entendido como superexaltatum, ao que dele deriva, mas é identificada à autoenunciação do próprio princípio: não se trata de aplicar ao princípio a negação entendida como privação ou exclusão, que caracteriza os entes finitos, tornando-o numa alteridade porém eminente, mas de sublinhar como o princípio define-se positivamente ao definir ao mesmo tempo tudo o que dele deriva, sem que o rejeito da oposição entre afirmação e negação implique a eliminação da discrepância entre expressão e enunciação ${ }^{22}$.

Deus não é simplesmente outro das oposições que caracterizam o mundo, pois, se sua transcendência se reduzisse a isso, seria uma entidade oposta a outras entidades, ainda que de natureza eminente: ao contrário, também Deus é outro da sua própria oposição ao mundo ${ }^{23}$. É outro precisamente porque não é outro: não é, portanto, o mero superexaltatum e o totalmente outro, mas o non aliud ${ }^{24}$. Por se distanciar da solução procliana do drama protológico, Nicolau de Cusa exibe o vínculo profundo que o une à tradição neoplatônica, em oposição à lógica aristotélica que enerva a tradição escolástica.

Recordando o exemplo Nicolau de Cusa da luz e das cores, é claro que, para um escolástico, a luz é outra coisa que as cores, tanto que a cor tem em si a causa de sua própria visibilidade; para um neoplatônico, ao con-

22 MONACO, Davide. Deus Trinitas, p. 215, n. 47.

23 NICOLAU DE CUSA. De principio, 35-36: «Mundus est infigurabilis figura et indesignabilis designatio. [...] Principium igitur, quod est ante contradictionem, omnia complicat, quae contradictio ambit. Principium videtur in oppositorum aequalitate».

24 A rejeição desta determinação do uno típica de Proclo, juntamente com a afirmação da coincidência do uno e dos muitos no início, sugere uma hipótese sugestiva: pode ser que Nicolau de Cusa tenha tido acesso aos manuscritos contendos as obras de Damáscio, levados à Itália por Basílio Bessarion e comentados por ele? O uso de termos como coniectura, bem como a retomada da dialética da implicatio-explicatio, parece traçar lexicalmente as correspondentes palavras gregas, que encontramos amplamente presentes em Damáscio. O último diádoco é o único entre os exegetas gregos a afirmar a necessidade de superar a dialética opositiva uno-muitos, que lança o princípio na aporia de ter de ser ao mesmo tempo absolutamente transcendente os principados e a causa imanente aos muitos. Além do léxico, Nicolau de Cusa parece estar unido a Damáscio pela tentativa de conceber um princípio unitário que desenvolve em si a dialética de uno-muitos. 
trário, a cor nada mais é do que luz colorida, isto é, uma das muitas maneiras pelas quais a essência hipostática da luz pode ser determinada (terminis lucis $)^{25}$. Consequentemente, não há diferença nítida entre substância e acidente, pois os acidentes, sejam eles necessários ou contingentes, nada mais são do que as formas concretas como a substância é dada: não há substâncias universais, nem diferenças específicas que se acrescentam ao gênero, mas singularidades irrepetíveis em que a diferença entre substância e acidente nunca é real ${ }^{26}$. Seguindo o paralelo, assim como a cor não só não pode ser vista, mas nem mesmo existe se a luz for removida, também nenhuma identidade ou alteridade pode existir sim o non aliud ${ }^{27}$; da mesma forma, assim como a luz não pode ser vista em si mesma, mas apenas terminada em uma de suas formas (em uma cor), também o non aliud não pode ser intuído em si mesmo, mas apenas como o princípio que brilha na entitas terminata. Em outras palavras: tendo experimentado a fatualidade do mundo, que se dá pela experiência, a mente volta ao non aliud como ao princípio de seu ser e de seu ser cognoscível.

A alteridade das entidades determinadas é o mesmo non aliud aparecendo como desconhecido: cada entidade contraída é o non aliud, mas concebido como aliud $^{28}$. A compreensão desse plexo, que Nicolau de Cusa define visio mentis ou acies mentis, sublima o conhecimento racional em uma contemplação que assume as feições da speculatio: um observar e um espiar que é ao mesmo tempo uma exploração, um exame e uma vigilância ${ }^{29}$. Se o ponto final da visão fosse um aliud, a mens estaría sempre na disjunção entre sujeito e objeto, na qual é impossível que o princípio da visão coincida

\footnotetext{
25 NICOLAU DE CUSA. De venatione sapientiae, VI 14, 12; De apice theoriae, VIII, 812.

26 NICOLAU DE CUSA. De coniecturis, II, 3: «Singularitas omnia singularizat». No respeito à concepção da relação entre substância e acidentes, Plotino já enfatizava que a dife-

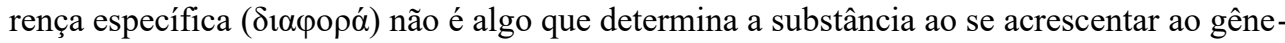
ro: Plotino entende o gênero não como uma mera possibilidade lógica, mas como um

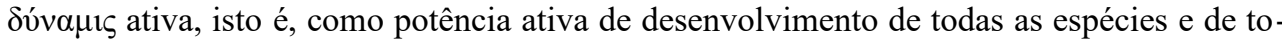
das as diferenças que podem ser abrangidas por ela; portanto, os atributos manifestam o que

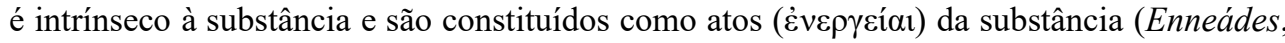
VI, 2, 14, 17). Sobre o assunto, cfr. CHIARADONNA, Riccardo. Sostanza, movimento, analogia, pp. 89 ss.

27 NICOLAU DE CUSA. De non aliud, IX, 5-8.

28 Ivi, VIII, 31, 9-11.

29 O termo latino specula indica o observatório e o mirante, especialmente o terreno alto e o pico de onde é possível monitorar e vigiar.
} 
com seu termo ${ }^{30}$. Sem o non aliud, nenhuma alteridade, portanto nenhuma identidade, poderia ser concebida. Assim Nicolau de Cusa funda a coincidência do non aliud com o outro extraordinário nomen Dei, o de possest: precisamente porque Deus é o poder absoluto que é ato absoluto, o princípio complica todas as coisas em si segundo todos os modos possíveis de ser e, portanto, não é outro deles. Se o finito é idêntico a si mesmo porque não pode ser outro senão o que é, o infinito é si mesmo pois esgota todas as possibilidades e é atualmente tudo o que pode ser. Ao contrário dos principiados, Deus não é si mesmo sendo diferente de outro.

Em sua última obra, o De apice theoriae, Nicolau de Cusa radicaliza essa posição: há uma e apenas uma quidditas, que é subsistência e hipóstase de todas as coisas; portanto, as singularidades são apenas modi essendi apparitionis do posse ipsum ${ }^{31}$. As coisas não são mais a especificação de uma das diferentes essências, mas as contrações da única potência segundo um certo grau de limitação, individual e irrepetível. A investigação sobre as quidditates leva ao reconhecimento da existência de uma quidditas absoluta, da qual as singularidades são modos de aparência: esta conclusão é o desenvolvimento do distanciamento da tradição escolástica já amadurecido no $D e$ Coniecturis, combinado com uma meditação profunda da filosofia de João Escoto Erígena. O cardeal enfatiza que toda pergunta pressupõe um contexto categórico no qual deve ser feita, tanto que a clássica quaestio An Deus sit pressupõe a entitas e a quidditas Dei, que não é uma de muitas substâncias, mas a única que realmente existe. Toda pergunta sobre Deus acaba por reconhecer que tem como pressuposto o que se propõe como objeto de pesquisa: portanto, a aplicação do procedimento da quaestio à esfera teológica é imprópria e só pode ser utilizada no campo da razão, regulada pelo princípio de não contradição ${ }^{32}$.

Porém, mesmo dizendo que Deus é non aliud, o enigma dessa substantivação não se desfaz: Deus é non aliud da criatura porque, em primeiro lugar, ele é não-outro: a ambiguidade do non permite manter Deus na trans-

\footnotetext{
30 NICOLAU DE CUSA. De non aliud, II, 7.

31 NICOLAU DE CUSA. De apice theoriae, IX, 9 ss. Cfr. De dato patris luminum, II, 97 : «Videtur igitur quod idem ipsum sit deus et creatura, secundum modum datoris deus, secundum modum dati creatura. Non erit igitur nisi unum, quod secundum modi diversitatem varia sortitur nomina».

32 NICOLAU DE CUSA. De coniecturis, 20, 4.
} 
cendência, sem negar sua imanência. Simplesmente, a dialética da transcendência e imanência não o determina, nem o captura. A visio Dei sempre permanece dentro do contexto da inspiração: tensão constante, praegustatio que nunca pode desistir do papel da scientia aenigmatica. Deus não é outra coisa das outras coisas e, portanto, é todas as coisas: porém, não como o outro é outro, mas como cada coisa é em si mesma non aliud. Deus não é outro do céu, mas também não é o céu, pois, de outra forma, ele seria um distinto entre os distintos, um oposto entre os opostos. Nas palavras de Meister Eckhart, Deus é indistinta distinctio, tanto a ponto de ser indistinto até mesmo com respeito ao nada: na verdade, mesmo o nada é nada, portanto non aliud quam nihil ${ }^{33}$. O distanciamento da tradição procliana do superexaltatum é evidente: se o princípio fosse reduzido à causa absolutamente transcendente, resultaria inevitavelmente ser o primeiro de uma série e o início de um processo, acabando capturado na relação com os principiados.

\section{Abyssus Trinitatis}

A faculdade cognitiva da mens humana encontra em seu auge a pura singularidade do posse ipsum, onde o ponto de potência máxima se converte na impotência total da docta ignorantia. Ao lado da denominação de non aliud, Nicolau de Cusa reconhece ao início a de possest: Deus é a totalidade atual do possível, pois todo possível, determinando-se, explicando-se, se distingue desde o início sem que o princípio seja distinto. Este é o nexo lógico que liga o conceito de possest ao de non aliud: se cada determinado, por a limitação que lhe inere, se distingue modalmente do princípio, o contrário o princípio, como possest que complica tudo em si, é não-outro das entidades contraídas.

A noção de non aliud representa o aspecto lógico do ato de criação entendido como contractio: aliud é o ens contractum, que se define como uma realidade limitada que se opõe a outras realidades limitadas; non aliud é a entitas absoluta, de modo que o non aliud aparece não só como aquela definição que, visto que precede a diferença entre definidor e definido, é a definição de si mesma, mas também como aquela definição pela qual a de-

33 NICOLAU DE CUSA. De non aliud, VII, 23, 3-4. 
terminação de todas as coisas fica definida. O não-outro é não outro que não-outro, assim que o outro é não outro que outro. A entidade determinada só pode ser definida, em relação à sua alteridade, pelo não-outro. O princípio aristotélico da não contradição, baseado na alteridade dos termos da oposição, pressupõe logicamente o princípio da determinação, que existe a partir da não alteridade, isto é, da coincidentia contradictoriorum do possest. Como aliud, cada termo da oposição pressupõe logicamente, para ser definido em sua especificidade, o não-outro, ou seja, a atualidade indeterminada do poder absoluto.

A precedência lógica do poder sobre o ato - o que pode ser está em ato, pois o que é impossível é precisamente o que nunca pode ser em ato implica imediatamente em Deus a coincidência de possibilitas, potentia e actus: o que Deus pode, o próprio Deus é e o faz, eternamente ${ }^{34}$. Portanto, Deus é todas as coisas e não pode ser diferente do que ele é ${ }^{35}$. Como, então, é possível evitar uma deriva panteísta? Especificando que Deus é de fato todas as coisas, mas não é uma coisa diferentemente do que é outra. Em outras palavras, se nas realidades contraídas a identidade depende do não ser a totalidade do contraditório, em Deus o ser-sol não está em contradição com o ser-beleza, pelo contrário, está necessariamente implicado na definição desse. Segue-se que Deus está livre de toda oposição (absolutum ab omni oppositione): Deus é todas as coisas eternamente e sem oposição, enquanto o cosmos é todas as coisas temporalmente e em oposição.

A noção de possest indica a identidade perfeita entre a essência divina e sua onipotência ${ }^{36}$. Nome de todos os substantivos e de nenhum nome em particular, o de possest permanece, no entanto, uma designação composta, sendo a crase das duas formas verbais posse e est. Um modo defeituoso de indicar não só a onipotência divina, mas também a sua eternidade: se Deus não pudesse ser, não seria, pois o princípio é imediatamente o que pode ser; tudo pode não ser, exceto o poder que torna todas as coisas possíveis $^{37}$. O princípio é aquela entidade cuja essência é o poder puro e atual, a

34 NICOLAU DE CUSA. Trialogus de possest, 6.

35 Ibid, 12.

36 MAAS, Frans. Divine omnipotence in the view of Nicholas of Cusa, pp. 177-188.

37 NICOLAU DE CUSA. Trialogus de possest, 27: «Mirabilis deus, in quo non-esse est essendi necessitas». Cfr. 53: «Ibi ignorantia est perfecta scientia, ubi non-esse est essendi necessitas, ubi ineffabile est nomen omnium nominabilium». 
totalidade dos possíveis em sua realidade. Cada ser é complicatus no início, dobrado e recolhido no ponto singular de máxima intensidade, absolutamente denso e, portanto, infinito. Deus é, por esta razão, o Ser Supremo, Aquele que tudo pode, posse infinito que contém todas as possibilidades: Deus sive potentia. Entre Deus e o mundo não há uma diferença ontológica, mas uma diferença modal, onde a contractio é o modo de tal diferencial: todo ser, como contração singular, nada mais é do que um modus existendi irrepetível do poder divino. Por isso, é fundamental, sobretudo do ponto de vista lógico, destacar como a filosofia de Nicolau de Cusa não cai no panteísmo: Deus é todas as coisas, mas tudo não é Deus, sendo ao invés a abertura de uma perspectiva definida sobre o poder infinito, absoluto e indeterminado.

A essência da Entidade suprema não coincide mais, como a tradição tomista queria, com a existência, mas com o poder. Trata-se, portanto, de esclarecer que, sendo Deus a infinita e, portanto, inesgotável, atualidade de seu próprio poder, não faz mais sentido colocar tanto a distinção entre a vontade e a onipotência do ato criador (daí a discordância escolástica entre a liberdade e a necessidade de ato criativo), bem como a distinção escolástica entre potentia ordinata e potentia absoluta (que só existe se houver o pressuposto da distinção entre a vontade e a onipotência). Tornando-se um ato infinito de criação, a onipotência esgota em si o conceito de vontade, que se esvazia completamente de sentido. Reelaborando a ideia neoplatônica de fluxus emanativus, reinterpretada radicalmente por Avicena, Nicolau de Cusa entende o ato de criação, ou seja, a expressão produtiva ilimitada do poder infinito, como a própria essência de Deus, para o qual mesmo apenas colocando o problema da vontade como distinta da onipotência, isto é, supor um instante em que Deus não poderia ter criado, é equivalente a negar sua própria essência.

O cardeal rejeita a separação entre essência e poder da matriz procliana: a substância de Deus é seu poder, tanto que sua causalidade não é outro senão ser a Trindade imanente no cosmos. A causalidade de Deus coincide com sua revelação. Se os escolásticos conceberam Deus como onipotente, Nicolau de Cusa passa a conceber Deus como a própria onipotência, isto é, pensa a onipotência como a própria essência de Deus. Quanto magis unita, tanto maioris virtutis: quanto mais simples algo é, mais poderoso é; conse- 
quentemente, só o que é mais simples, o autounum, pode ser onipotent ${ }^{38}$. O posse absolutum de Deus é a coincidência perfeita de posse facere e posse fieri, tanto que a criação se estrutura como desdobramento do que em Deus já está presente eternamente em ato. Não a criação de uma alteridade a partir de outro de si mesmo, mas a explicitação do complicado ${ }^{39}$. A consequência maior é o esmagamento do ato criativo sobre a noção neoplatônica de procissão, junto - e isso é surpreendente em um neoplatônico cristão - com a negação da transcendência absoluta do princípio ${ }^{40}$. Nicolau de Cusa tenta unir a irredutibilidade de Deus a qualquer proporção (entre o infinito e o finito há um abismo) e a presença do princípio em todas as coisas.

$\mathrm{O}$ de non aliud, bem como os de possest e posse ipsum, é o conceito absoluto que complica todo conceito: porém, uma mente finita e necessariamente normatizada pelo princípio da contradição concebe essa noção, mas não a compreende. $\mathrm{O}$ non aliud requer a remoção de qualquer nomeação, incluindo aquela que diz que Deus é unitrino. O recurso analógico à matemática para justificar a Trindade divina parece inoportuna, especialmente depois que o valor do raciocínio analógico foi negado em virtude do apofatismo e que o cardeal alertou contra o perigo de entender a relação intra-trinitária como uma relação numérica. Seguindo o discurso, tendo voltado por abstração ao princípio simples, é inevitável concluir que sua simplicidade não é mais una do que é trina ${ }^{41}$ : daí não segue, porém, que seja una e trina.

Os nomes de Pai, Filho e Espírito são adequados no contexto da economia trinitária, isto é, quando se deseja expressar a relação entre o princípio e o mundo que se realiza na criação; porém, no contexto da Trindade imanente, ou seja, no contexto das relações mútuas entre as Pessoas divinas, essas denominações revelam-se imperfeitas, tanto que o cardeal prefere utilizar as duas tríades unitas-aequalitas-connexio e hoc-id-idem. A rejeição ao procedimento aristotélico da definitio, que foi discutida no início, é ditada pelo fato de a definitio expressar nada mais do que o ser idêntico a si mesma de cada entidade. É precisamente o non aliud, que se destaca em to-

\footnotetext{
38 NICOLAU DE CUSA. De beryllo, XX, 11-13.

39 NICOLAU DE CUSA. Trialogus de possest, 73.

40 Ibid, 69: «Haec igitur vera sunt quae sancti asserunt. Aiunt enim deum esse quantum sine quantitate, qualem sine qualitate et ita de omnibus».

41 Ibid, 45.
} 
das as tentativas de definir a quidditas, a ser o pressuposto oculto da investigação cognitiva. A mens conhece pelas definições, mas apenas sobre o fundamento do non aliud, que se revela um verdadeiro aenigma. O non aliud não é apenas um novo nome que pode ser indevidamente atribuído a Deus, mas também a forma de todo o conhecimento que pode ser adquirido pelo homem.

O fato de Nicolau de Cusa não ter incluído o De non aliud na coleção de seus escritos é eloquente, ainda que essa noção apareça como um terceiro campo de investigação no De venatione sapientiae. Sintoma de que ou o cardeal contemplou um retrabalho da obra, ou que a considerou constitutivamente não perfectível e, portanto, como um campo de investigação destinado ao intellectus e irredutível à escrita. Com o conceito do non aliud, Nicolau de Cusa pretende superar as aporias dos neoplatônicos que, concebendo o princípio como puro idem, não conseguiram justificar a relação do princípio com os principiados e a passagem do uno aos muitos. Por meio da noção de aequalitas, o cardeal medeia o Deus absconditus neoplatônico e o Deus revelatus cristão, sem, contudo, se livrar das aporias dos mestres gregos: se as Pessoas divinas são todas igualmente aequalitas, de onde sua distinção mútua? O campo da aequalitas não dará mais frutos, tanto que no $D e$ venatione sapientiae se tornará um atributo somente do Filho, em oposição à unidade que caracteriza o Pai.

No conceito de non aliud, o cardeal descobre um elemento cuja profundidade ontológica, mediada pela linguagem, espelha seu valor gnosiológico. Retomando um dos elementos fundamentais da epistemologia neoplatônica, ele faz do non aliud o meio de assimilação ao divino, como o único nome que permite aspirar à não alteridade entre o conhecedor e o conhecido, entre o nome e a coisa, entre o definidor e o definido ${ }^{42}$. Como uma definição pode aspirar a tanto? Voltando-se reflexivamente sobre si mesma: só a definição que se define, e que não pressupõe seu objeto como outro, externo e oposto, só tal definição pode atingir esse fim, combinando o máximo de transcendência com o máximo de imanência, pois nela o definidor e o de-

42 NICOLAU DE CUSA. De non aliud, 124, 10-11, propositio XIX: «Hoc est enim intelligere, scilicet intelligibilia a se non alia facere». Para aprofundar o assunto, cfr. DUCLOW, Donald F. The Analogy of the Word. In: DUCLOW, Donald F. Masters of Learned Ignorance: Eriugena, Eckhart, Cusanus. Aldershot: Ashgate, 2006, pp. 255-274. 
finido coincidir ${ }^{43}$. Na identidade de definiens, definitum e definitio, que é a imagem da pericorese divina, o saber se conhece e sabe conhecer o absoluto. O non aliud não pode ser definido por nada que seja aliud, portanto, é necessariamente autodefinido na fórmula non aliud est non aliud quam non $\operatorname{aliud}^{44}$. Todas as coisas, ínfimas ou sublimes que sejam, não são outra coisa senão o non aliud que se define ${ }^{45}$.

O non aliud está semanticamente envolvido na definição de todas as coisas e é, portanto, o conceptus absolutus. Precisamente esta fórmula, que se aplicada às realidades contraídas as define em sua limitação para a qual elas mesmas não são a totalidade de seu próprio contraditório (cada aliquid é um aliud quid), se aplicada ao princípio dissolve a lógica da oposição. Não sendo capaz de apreender Deus como ele é em si mesmo, a mens o agarra nos alia como o que é non aliud ${ }^{46}$. Se por meio do idem a entidade finita exibe sua própria identidade consigo mesma como um mero fato, em virtude do non aliud tal identidade se encontra reflexivamente fundada no início na forma de uma auto-relação, na imagem da pericorese divina ${ }^{47}$ : quem não entende a evolução que leva a filosofia de Nicolau Cusa do idem do De Genesi ao non aliud, segundo as próprias palavras do cardeal, não entende que Deus não é apenas o princípio único, mas também o princípio trino ${ }^{48}$. O non aliud é o que nada falta, já que a alteritas é a forma primária de falta, visto que cada entitas contracta é deficiente do que se caracteriza como outra alteridade determinada. Se o céu nada mais é do que o céu, supondo que o non aliud fosse outro que o céu, o céu não poderia ser o céu ${ }^{49}$; se o uno falhasse, continuaria havendo um caos infinitamente múltiplo, ao passo que, se o non aliud falhasse, mesmo esse caos não poderia existir, exatamente como o $\operatorname{nada}^{50}$.

43 STALLAMACH, Josef. Ineinfall der Gegensätze und Weisheit des Nichtwissens, p. 63.

44 NICOLAU DE CUSA. De non aliud, I, 4.

45 Ivi, 118, propositio XII: «Qui videt, quoniam ipsum 'non aliud' sui et omnium est definitio et definitum, ille in omnibus, quae videt, non nisi 'non aliud' videt se ipsum definiens. Nam quid videt in aliud nisi 'non aliud' sese definiens? Quid aliud in caelo quam 'non aliud' se ipsum definiens? Et de omnibus eodem modo».

46 Ibid, III, 10.

47 CÜRSGEN, Dirk. Die Logik der Unendlichkeit, p. 102.

48 NICOLAU DE CUSA. Cribratio Alkorani, 86-87.

49 NICOLAU DE CUSA. De non aliud, VI, 20.

${ }^{50}$ Ivi, VII, 23-24. 
Falando mais propriamente, o non aliud não é um substantivo, mas uma substantivação de uma locução adverbial, uma função linguística dinâmica que expressa a tradução de uma operação de definição universal por meio de um substantivo (indicativo, neste sentido, o uso no texto latino do artigo definido $(i)^{51}$ : o non aliud não uma entidade que teria a propriedade de ser não outra, mas uma realidade dinâmica estruturalmente relacional que define si mesma e cada coisa sem colocar nenhuma alteridade. Recusando um caráter nominal ao non aliud, Nicolau de Cusa faz dele um Sprachspiel onde a visio Dei coincide com a análise linguística. O aliud não coincide com o Ě $\varepsilon \varepsilon \rho o v$, isto é, com algo de outro numa correspondência biunívoca que o delimita, mas com o ở $\lambda \lambda_{0}$, que é alteridade indeterminada; o non não se refere a uma negação exclusiva ou privativa, mas a uma negação que inclui o que nega em sua própria positividade ${ }^{52}$.

O non aliud não é o nome de Deus, que não tem nome. Como sugere um dos títulos alternativos atribuídos à obra, o non aliud nada mais é do que directio speculantis. Essa noção não indica uma propriedade do princípio, embora eminente, mas indica sua quidditas, coincidindo com o poder de gerar o aliud não a partir dum aliud, mas ex sese. O non aliud é a coincidência e a contradição de particularidade e universalidade: um nome puramente negativo de Deus, é ao mesmo tempo uma condição de possibilidade de toda nomeação das criaturas. O non aliud é virtus specificandi: é o indiferente que dá origem a todas as diferenças e que só nas diferenças pode ser apreendido como aquilo que as nega. Nicolau de Cusa quebra assim a equação que identifica a expressão e a enunciação: embora seja inexprimível, o princípio é dito em todas as coisas. A entidade finita tem apenas uma conotação negativa: o finito é o que não é non aliud.

No entanto, se cai aqui no círculo de uma dupla negatividade: se infere o non aliud apenas a partir do aliud, sem que este seja algo positivo, sendo por sua vez a negação do non aliud. Assumindo a forma de uma predicação reflexiva de si mesmo, o non aliud define todas as coisas e si mes-

51 DANGELMAYR, Siegfried. Gotteserkenntnis und Gottesbegriff in den philosophischen Schriften des Nikolaus von Kues. p. 255.

52 Sobre o assunto, cfr. WYLLER, Egil A. Zum Begriff "non aliud” bei Cusanus, pp. 419443; Nicolaus Cusanus "De non-aliud” und Platons Dialog "Parmenides”, pp. 239-251; “Identität und Kontradiktion. Ein Weg zu Cusanus' Unendlichkeitsidee”, pp. 104-120. 
mo: o movimento da definitio sui, que é um reflexo da pericorese divina, permanece algo incompreensível para a mens contracta, assumindo o papel de directio para a aproximação a Deus e a sua natureza de autodeterminação trinitária. Deus já não se arrisca a ser reduzido ao idem da tradição procliana, pois encerra em si a dialética permanência-procissão-conversão: sendo ele mesmo (Pai), o princípio se coloca como outro (Filho), para se revelar imediatamente como non aliud em virtude do motus definitivus (Espírito). A geração do Filho revela a necessidade do caráter trinitário do princípio: se o non aliud não incluísse a alteridade em si mesmo, isto é, se não colocasse a diferença no ato de negá-la, seria oposto a ela e, portanto, não seria mais o non aliud, mas uma forma eminente de alteritas.

O conceito do non aliud é a noção que interrompe a circularidade autorreferencial da alma: se todos os conceitos se referem as entitates cuja enunciação coincide com a expressão, o non aliud rompe esta equação, referindo-se a algo que não está delimitado e que, portanto, é incompreensível. No non aliud, que é um conceito da mente humana, o ser se revela transbordando do pensamento. Segue-se que a transcendência divina não deve ser concebida de acordo com a lógica da oposição ${ }^{53}$. Todos os nomina Dei, incluindo o possest, conduzem a Deus como outra coisa, arriscando esmagar a novitas cristã na noção dum princípio impessoal típico do neoplatonismo; o non aliud, ao contrário, permite de evitar a compreensão unilateral da dialética da transcendência e da imanência, ao mesmo tempo que exibe seu caráter trinitário. Um elo une o idem absolutum e o non aliud: o non aliud não pode ser aliud, isto é, deve necessariamente ser ele mesmo; é o não-ser dos alia, dos finitos, nunca de si mesmo. Autêntico principium essendi et cognoscendi de toda a realidade, o non aliud é a raiz que permite pensar todas as formas de identidade e alteridade. O nome de Deus, porém, não é Deus: embora designado como conceito absoluto, o non aliud permanece um ato definidor, ou seja, uma circunscrição da quidditas que a torna uma realidade limitada e contraída ${ }^{54}$.

\footnotetext{
53 NICOLAU DE CUSA. De venatione sapientiae, XIV, 41, 10-22.

$54 \mathrm{O}$ fato é que a definição de non aliud limita de uma forma totalmente diferente do que as definições lógicas: estas definem como uma superfície triangular é determinada por meio das linhas que a circunscrevem, enquanto o non aliud define como constrói o objeto de realidade de definição. O non aliud não é, portanto, reduzido a ratio cognoscendi, sendo também a ratio essendi de tudo o que existe. Cfr. NICOLAU DE CUSA. De non aliud, XXII,
} 
Este elemento justifica a peculiar reinterpretação da tradição mística neoplatônica, especialmente de Dionísio o Areopagita: a coincidentia contradictoriorum, que faz do princípio uma oppositorum oppositio sine oppositione e uma contradictoriorum contradictio sine contradictione, permite, por um lado, libertar o discurso teológico da submissão ao princípio da não contradição, que o cardeal considerava o resultado final da recuperação da lógica aristotélica na escolástica, por outro lado evitar a precipitação da reflexão no puro silêncio entendido como negação das palavras e do raciocínio. Afastando-se desses perigos especulares, por meio de uma theologia sermocinalis Nicolau de Cusa busca não a redução de Deus ao discurso, nem a negação da palavra, mas a possibilidade de nomear Deus sem esgotálo semanticamente ${ }^{55}$ : em todo termo, Deus é entendido como insignificante. Basicamente, o cardeal tenta mediar a demanda realista da pesquisa teológica com a atenção à análise linguística típica do nominalismo, fazendo da $s a-$ pientia uma sapida scientia.

Apesar disso, a conclusão do itinerário especulativo é tão desorientadora quanto inevitável. A questão da qual partimos, isto é, se devemos dizer que Deus é uno e trino ou trino e uno, é resolvida no apofatismo mais radical: Deus em si mesmo não é nem uno nem trino, uma vez que esses nomes são tirados da criação e portanto, eles meramente apontam para Deus como Criador, não Deus em si mesmo ${ }^{56}$. A virada brusca no tratamento do posse que está no centro do De venatione sapientiae dá a figura dessa oscilação aporética: se no Trialogus de possest Deus foi definido como a coincidência perfeita do posse facere e do posse fieri, no testamento filosófico do cardeal o posse fieri passa a assumir um estatuto intermediário, sendo identificado com o mundo na sua eterna disponibilidade de ser determinado nas singularidades que representam o posse factum.

Com a teoria do posse ipsum, na qual a resolutio filosófica atinge sua forma extrema, Nicolau de Cusa reabre a aporética que esperava ter resolvido. O posse ipsum, como potência de todo poder (posse omnis potentiae), se mostra como pressuposto de todo ser e poder de pensar, constituindo-

101.

55 SENGER, Hans Gerhard. Die Präferenz für Ps. Dionysius bei Nicolaus Cusanus und seinem italienischen Umfeld, pp. 505-539.

${ }^{56}$ NICOLAU DE CUSA. De pace fidei, VII, 21; Cribratio Alkorani, II, 1, 882 ss. 
se como uma espécie de abismo que precede o Deus-Trinitas em sua determinação de posse facere. Não se pode pensar mais do que o posse ipsum, pois todo ser capaz de pensar o pressupõe: sua indubitabilidade também põe em xeque a dúvida mais radical, pois mesmo a possibilidade de duvidar pressupõe o posse ipsum. O exercício da dúvida radical é, portanto, a forma suprema que confirma a certeza do posse ipsum, ao mesmo tempo que o liberta da necessidade de sua constituição trinitária.

Dada a noção que concebe o princípio como potência absoluta, o Reino de Deus é representado pela figura do Rei no próprio ato de reinar, ou seja, no ato de criar e de governar o mundo eternamente. As metáforas escolásticas do Deus soberano e do Deus relojoeiro, expressões da diferencia entre a potentia absoluta e a potentia ordinata, são totalmente reabsorvidas na figura do Rex regnans, para quem a legitimidade de reinar nada mais é do que reinar: o Reino é infinito, assim como interminatus é o ato da cogitatio que se aproxima do início e que faz do homo viator um homo venator.

Recebido em 09/01/2021 e aprovado em 28/02/2021

\section{BIBLIOGRAFIA}

AGOSTINHO DE HIPONA. Epistula 130. Edição: Al. Goldbacher. Vindobonae - Lipsiae: Corpus Scriptorum Ecclesiasticorum Latinorum (44), 1904, p. $40-77$.

AGOSTINHO DE HIPONA. De natura et origine animae. Edição: Carolus F. Urba et Josephus Zycha. Vindobonae - Lipsiae: Corpus Scriptorum Ecclesiasticorum Latinorum (60), 1913, p. 301-420.

ATANÁSIO DE ALEXANDRIA. Contra Arianos I. Edição: Karin Metzler. Berlin - New York: de Gruyter (Werke, II), 1998.

BASÍLIO DE CESAREIA. De Spiritu Sancto. Edição: Benoît Pruche. Lyon: Cerf (Sources Chrétiennes 17 bis), 1968².

BOAVENTURA DE BAGNOREGIO. Breviloquium. Edição: Frati Editori Quaracchi. Quaracchi: Bonaventurae Opera Theologica Selecta (V), 1964.

CHIARADONNA, Riccardo. Sostanza, movimento, analogia. Plotino critico di Aristotele. Napoli: Bibliopolis, 2002. 
COSTANTINO IMP., "Epist. ad episc. et pleb". (apud Gelas, H.E., II, 36, e Sokrat., H.E., I, 9). In: PORFÍRIO, Contra Christianos. Edição: Giuseppe Muscolino. Milano: Bompiani, 2009, p. 136-137.

CÜRSGEN, Dirk. Die Logik der Unendlichkeit: Die Philosophie des Absoluten im Spätwerk des Nikolaus von Kues. Frankfurt am Main: Peter Lang, 2007.

DANGELMAYR, Siegfried. Gotteserkenntnis und Gottesbegriff in den philosophischen Schriften des Nikolaus von Kues. Meisenheim am Glan: A. Hain, 1969.

DANTE ALIGHIERI, Purgatorio. Milano: Mondadori, 2016.

DUCLOW, Donald F. "The Analogy of the Word". In: DUCLOW, Donald F. Masters of Learned Ignorance: Eriugena, Eckhart, Cusanus. Aldershot: Ashgate, 2006, p. 255-274.

GREGÓRIO DE NAZIANZO. Epistula 101. Edição: Paul Gallay. Lyon: Cerf (Sources Chrétiennes 208), 1974.

MAAS, Frans. "Divine omnipotence in the view of Nicholas of Cusa". In: BOCKEN, Inigo (ed.), Conflict and Reconciliation: Perspectives on Nicholas of Cusa. Leiden: Brill, 2004, pp. 177-188.

MONACO, Davide. Deus Trinitas: Dio come non altro nel pensiero di Nicolò Cusano. Roma: Città Nuova, 2010.

NICOLAU DE CUSA. Opera omnia. Edição: Academiae Litterarum Heidelbergensis. Heidelberg, 1932-2010.

NICOLAU DE CUSA. Acerca de lo no-otro o de la definición que todo define. Edição: Jorge M. Machetta y Klaus Reinhardt. Buenos Aires: Biblos, 2008.

PLOTINO. Enneádes. Edição: Paul Henry e Hans-Rudolf Schwyzer. Oxford: Clarendon Press, 1964-1982.

SENGER, Hans Gerhard. "Die Präferenz für Ps. Dionysius bei Nicolaus Cusanus und seinem italienischen Umfeld". In: BOIADJIEV, TSòcho, KAPRIEV, Georgi, SPEER, Andreas (eds.). Die Dionysius-Rezeption im Mittelalter. Turnhout: Brepols, 2000, p. 505-539.

STALLAMACH, Josef. Ineinfall der Gegensätze und Weisheit des Nichtwissens: Grundzüge der Philosophie des Nikolaus von Kues. Münster: Aschendorff, 1989.

TOMÁS DE AQUINO. Summa theologiae. Edição: Commissio Leonina. Romae: Editio Leonina (IV-XII), 1888-1906. 
TOMÁS DE AQUINO. Quaestiones disputatae de veritate. Edição: Antoine Dondaine. Romae: Editori di san Tommaso (XII, 1-3), 1972-1976.

WYLLER, Egil A. "Zum Begriff "non aliud" bei Cusanus". In: SANTINELLO, Giovanni (ed.), Cusano agli inizi del mondo moderno. Firenze: Sansoni, 1970, p. 419-443.

WYLLER, Egil A. Nicolaus Cusanus "De non-aliud" und Platons Dialog "Parmenides". In: DÜRING, Klaus, KULLMANN, Wolfgang (eds.), Studia platonica. Amsterdam: John Benjamins, 1974, pp. 239-251.

WYLLER, Egil A. "Identität und Kontradiktion. Ein Weg zu Cusanus' Unendlichkeitsidee". Mitteilungen und Forschungsbeiträge der CusanusGesellschaft, 15, 1982, pp. 104-120. 